\title{
Betacyanin accumulation and guaiacol peroxidase activity in Beta vulgaris L. leaves following copper stress
}

\author{
Janet María León Morales, Mario Rodríguez-Monroy, Gabriela Sepúlveda-Jiménez* \\ Department of Biotechnology, Center of Biotic Products Development, National Polytechnic Institute, CeProBi 8, San Isidro, Yautepec, Morelos 62731, México
}

\section{Abstract}

The effect of copper stress on betacyanin accumulation and guaiacol peroxidase (GPOD) activity in leaves of different age was evaluated in red beet (Beta vulgaris L. var. Crosby Egyptian) plants. In hydroponic culture, plants were treated with $0.3 \mu \mathrm{M}$ (control), $50 \mu \mathrm{M}, 100 \mu \mathrm{M}$, and $250 \mu \mathrm{M}$ of $\mathrm{CuSO}_{4}$ for 6 days. Copper was taken up and accumulated in old roots but was not translocated to leaves. However in young leaves, the increase of lipid peroxidation and reduction of growth were evident from day 3 of copper exposure; whereas in old leaves, the lipid peroxidation and growth were the same from either copper-treated or control plants. In response to copper exposure, the betacyanin accumulation was evident in young leaves by day 3 , and continued to increase until day 6. Betacyanin only were accumulated in old leaves until day 6, but the contents were from 4 to 5 times lower than those observed in young leaves at the same copper concentrations. GPOD activity increased 3.3- and 1.4-fold in young and old leaves from day 3 of copper treatment respectively, but only in the young leaves was sustained at the same level until day 6 . Old roots shown betacyanin in the control plants, but the betacyanin level and growth were reduced with the copper exposure. In contrast, young roots emerged by copper effect also accumulated copper and showed the highest betacyanin content of all plant parts assayed. These results indicate that betacyanin accumulation and GPOD activity are defense responses to copper stress in actively growing organs.

Keywords: oxidative stress, betacyanin, abiotic stress, antioxidant compound, copper

\section{Introduction}

High levels of copper in the environment may originate from natural sources, industrial activity, or the use of fungicides in agriculture [1]. Copper is an essential plant micronutrient, involved in the photosynthetic electron transport, where plastocyanin is a copper-binding protein. It is also cofactor of several enzymes such as cytochrome oxidase, superoxide dismutase and ascorbate oxidase [2]. The exposure of plants to copper concentrations higher than those required for optimal growth results in phytotoxicity, causing growth inhibition and cell death. The inhibitory effects of copper on leaf growth in Arabidopsis thaliana arise from inhibition of cell expansion [3]. Inhibition of primary root growth by copper could result from the arrest of cellular division and/or nuclear membrane damage in the meristematic zone [4,5], whereas the stimulation of cell division at sites distant from root tips is associated with changes in the distributions of auxin and cytokinin,

*Corresponding author. Email: gsepulvedaj@ipn.mx

This is an Open Access digital version of the article distributed under the terms of the Creative Commons Attribution 3.0 License (creativecommons.org/licenses/by/3.0/), which permits redistribution, commercial and non-commercial, provided that the article is properly cited. which increase lateral root formation [6]. These observations, together with the demonstration that morphogenic growth responses to excess copper resemble those induced by sources of oxidative stress, such as the herbicide paraquat or tertbutylhydroperoxide, an analogue of hydrogen peroxide $\left(\mathrm{H}_{2} \mathrm{O}_{2}\right)$ [3], suggest that the reorientation of plant growth in response to copper toxicity involves changes in phytohormone distribution and the metabolism of reactive oxygen species (ROS).

Elevated levels of intracellular copper generate oxidative stress through increasing the levels of ROS, which in turn increase rates of lipids and proteins oxidation [7-9]. The quantification of lipid peroxidation has been used as an indicator of oxidative damage in leaves and roots of copper-exposed plants [7,10-14]. Peroxidases such as guaiacol peroxidases (GPOD) are also considered to be reliable markers of metal stress. These enzymes catalyze the oxidation of several substrates, such as phenolics, lignin precursors, auxin, and secondary metabolites [15]. Given that copper stimulates the activities of coniferyl alcohol peroxidase and indole-3-acetic acid oxidase in Pisum sativum roots [16], it has been proposed that GPOD could contribute to cell wall lignification, growth regulation and antioxidant defense responses $[11,17,18]$.

Several studies have demonstrated a differential toxicity of copper in leaves. Copper exposure inhibited the growth of Phaseolus coccineus young leaves, but the growth of older leaves remained unchanged even though they showed evidence of chlorosis [19]. Copper inhibited the growth of Cucumis sativus young leaves, but had no effect on the area of mature 
leaves, even though photosynthesis was inhibited [20]. At the cellular level, chlorophyll breakdown and lipid peroxidation in copper-exposed segments of old leaves were higher than in young leaves segments of Avena sativa [21]. However, studies concerning the relationship between toxicity of copper and the antioxidant responses in plant organs at different developmental stages are scarce. For example, Luna et al. [21] reported that young leaves segments of Avena sativa exposed to copper exhibited less oxidative damage and a higher increase in the activity of superoxide dismutase than segments of old leaves. Although it was reported that exposure of Morus alba plants to copper caused uniform yellowing in old leaves, the effects of copper toxicity on the activities of antioxidant enzymes were only evaluated in younger leaves [22].

The accumulation of secondary metabolites with antioxidant activity is also a defense response to copper exposure. Oxidative stress caused by exposure to high levels of copper was implicated in the accumulation of phenolic compounds in Withania somnifera plants and the accumulation of polyamines in Triticum aestivum plants $[11,13]$. Furthermore, incubation of wheat leaf segments in the presence of spermine prior to copper treatment prevented subsequent lipid peroxidation [13]. The copper accumulation in roots and leaves of Matricaria chamomilla increased the content of phenolic acids that may contribute to the avoidance of lipid peroxidation in leaves [12,23]. In Raphanus sativus shoots, the increases in cinnamic and benzoic acid derivatives and reduction in levels of ascorbate are dependent of the copper concentration. In this study a $\mathrm{H}_{2} \mathrm{O}_{2}$ detoxification system was suggested, that could be formed by phenolic acids and reduced ascorbate and a peroxidase [14]. The accumulation of secondary metabolites with antioxidant activity in response to copper stress may depend of the developmental stage of the organ. Skórzyńska-Polit et al. [24] reported that the increase in the flavonol content was higher in young leaves than in old leaves of $P$. coccineus after copper treatment.

Betacyanins are tyrosine-derived chromoalkaloids synthesized by members of nine families of the order Caryophyllales [25]. In vitro assays demonstrated the antioxidant activity of betacyanin present in Beta vulgaris L. roots [26,27]. Betacyanin accumulation in plants has been linked with oxidative stress factors such as exposure to UV radiation in Mesembryanthemum crystallinum [28], wounding and bacterial infiltration in leaves of Beta vulgaris L. [29], as well as low temperatures, high salinity and exposure to exogenous $\mathrm{H}_{2} \mathrm{O}_{2}$ in Suaeda salsa $[30,31]$. However, the effect of copper on betacyanin accumulation in leaves and roots at different developmental stages and its relationship with the toxicity symptoms has not been evaluated. Here we report for first time that the betacyanin accumulation and GPOD activation are defense responses in actively growing organs in plants of Beta vulgaris L. exposed to copper.

\section{Material and methods}

\section{Seed germination and plant material}

Seeds of red beet (Beta vulgaris L. var. Crosby Egyptian) were germinated between paper towels moistened with distilled water in darkness at room temperature $\left(25 \pm 2^{\circ} \mathrm{C}\right)$. Fiveday-old seedlings were transplanted into plastic pots filled with a sterile mixture of peat moss and metromix (1:3, w/w). Plants were grown at $21 \pm 2^{\circ} \mathrm{C}$, with $60 \%$ relative humidity and a $16 \mathrm{~h}$ light/ $8 \mathrm{~h}$ dark photoperiod, with a photosynthetic photon flux density of $68 \mu \mathrm{mol} \times \mathrm{m}^{-2} \times \mathrm{s}^{-1}$ provided by fluorescent white light lamps (Osram L140W/20, Danvers, MA). Plants with three pairs of true leaves were treated with copper. Leaves between 7 and 17 days of age were classified as young, and those 34-36 days of age were classified as old leaves. Roots present at the time that treatment was initiated were referred to as old roots, and roots that emerged within 6 days of copper treatment were referred to as young roots.

\section{Copper treatment}

Roots of 7-week-old plants were washed twice with deionised water in order to eliminate excess growth substrate. Plants were then transferred to boxes (10 plants/box) containing Hoagland nutritive solution ( $\mathrm{pH} 5.2 \pm 0.02$ ), modified to contain $0.33 \mathrm{mM} \mathrm{NH}_{4} \mathrm{H}_{2} \mathrm{PO}_{4}, 1.3 \mathrm{mM} \mathrm{CaCl}_{2}, 0.66 \mathrm{mM} \mathrm{MgSO}_{4}$, $2 \mathrm{mM} \mathrm{KNO}_{3}, 46 \mu \mathrm{M} \mathrm{H}_{3} \mathrm{BO}_{3}, 0.8 \mu \mathrm{M} \mathrm{ZnSO}_{4}, 0.88 \mu \mathrm{M} \mathrm{MnCl}_{2}$, $0.012 \mu \mathrm{M} \mathrm{Na} \mathrm{Mo}_{2} 4 \mathrm{H}_{2} \mathrm{O}, 1.44 \mu \mathrm{M}$ Fe-EDTA. The copper concentration in the control condition was $0.3 \mu \mathrm{M} \mathrm{CuSO}_{4}$. After a 4 -days adaptation period, plants were treated with copper for 6 days by adding additional $\mathrm{CuSO}_{4}$ to the media. The copper concentrations evaluated were $50 \mu \mathrm{M}, 100 \mu \mathrm{M}$, and $250 \mu \mathrm{M}$ $\mathrm{CuSO}_{4}$, and the nutritive solution was renewed every 3 days. For all determinations, tissue samples were collected from both old and young leaves and roots.

Levels of betacyanin, copper, and lipid peroxidation were determined at the time that treatments began, and at 3 and 6 days after exposure to copper. Chlorophyll content, leaf area and root length were measured after 6 days of treatment.

\section{Copper content}

Metal ions adhered to all roots were removed by incubating the roots in deionised water for $30 \mathrm{~min}$, followed by incubation $10 \mathrm{mM} \mathrm{CaCl}_{2}$ for $10 \mathrm{~min}$. Leaves and roots were dried in an oven (Lab-Line Instruments, Inc., Melrose Park, IL) at $70^{\circ} \mathrm{C}$ for $24 \mathrm{~h}$ prior to being ground using a pestle and mortar. The powder was digested with $\mathrm{HNO}_{3}: \mathrm{H}_{2} \mathrm{O}_{2}(1: 1, \mathrm{v} / \mathrm{v})$ mixture in a MARSXP15000 Plus microwave (CEM Corporation, Matthews, NC) at $150^{\circ} \mathrm{C}$ for $15 \mathrm{~min}$. Total copper concentration was determined by atomic absorption spectroscopy using a Varian SpectrAA 55B flame spectrometer (Varian, Inc., Palo Alto, CA) at a wavelength of $324.8 \mathrm{~nm}$. Experiments were performed at the Chemical Laboratory of the Science Institute, Benemérita Universidad Autónoma de Puebla, Mexico. Data were expressed as $\mu \mathrm{g}$ copper $\times \mathrm{g}^{-1}$ dry weight $(D W)$.

\section{Determination of total chlorophylls}

Two leaf discs $(0.5 \mathrm{~cm})$ were cut, frozen in liquid nitrogen and then immediately homogenized in $1 \mathrm{~mL}$ of $80 \%$ acetone. After centrifugation at $15000 \times \mathrm{g}$ for $15 \mathrm{~min}$, the absorbance of the supernatant at 646.8 and $663.2 \mathrm{~nm}$ was measured using a Genesys 2 spectrophotometer (Thermo Spectronic, Madison, WI). Total chlorophyll content was calculated according to the equations proposed by Lichtenthaler [32].

\section{Lipid peroxide determination}

Lipid peroxidation was determined by measuring thiobarbituric acid reactive substances (TBARS) as described previously Alia et al. [33]. Six $0.5 \mathrm{~cm}$ discs of fresh leaves were homogenized in $1 \mathrm{~mL}$ of trichloroacetic acid (5\%, w/v) and extracts were centrifuged at $15000 \times g$ for $10 \mathrm{~min}$. The supernatant was transferred to vials containing $1 \mathrm{~mL}$ of reaction buffer $(0.5 \%$ thiobarbituric acid in $20 \%$ trichloroacetic acid 
solution), incubated for $30 \mathrm{~min}$ in a water bath at $95^{\circ} \mathrm{C}$, and cooled in an ice bath for $10 \mathrm{~min}$. Samples were centrifuged at $9500 \times g$ for $10 \mathrm{~min}$ at $15^{\circ} \mathrm{C}$. The absorbance of the supernatant was measured at $532 \mathrm{~nm}$, and the non-specific absorbance at $600 \mathrm{~nm}$ was subtracted. Results were expressed as malondialdehyde (MDA) equivalents in $\mathrm{nmol} \times \mathrm{g}^{-1}$ fresh weigh $(F W)$ and calculated using a standard curve prepared using known concentrations of MDA.

\section{Quantification of betacyanins}

Root segments (ca. $25 \mathrm{mg}$ ) or four $0.5 \mathrm{~cm}$ disc of fresh leaves were ground with a pestle and motor-driven grinder (SigmaAldrich Co., St. Louis, MO) in Eppendorf tubes. Samples were homogenized with $1 \mathrm{~mL}$ distilled water, and incubated at $85^{\circ} \mathrm{C}$ in agitation $(300 \mathrm{rpm})$ for $5 \mathrm{~min}$. Extracts were centrifuged at $9500 \times g$ for $10 \mathrm{~min}$ at $25^{\circ} \mathrm{C}$. The absorbance of the supernatant was measured at $540 \mathrm{~nm}$, and the betacyanin content was calculated according to standard curve with known concentrations of betanin purified by high-performance liquid chromatography as described previously Schwartz and von Elbe [34]. Data were expressed in mg betanin equivalents $\times$ $\mathrm{g}^{-1} F W$.

\section{GPOD activity}

For each sample, three $0.5 \mathrm{~cm}$ discs from leaves were frozen in liquid nitrogen and ground in Eppendorf tubes with $0.005 \mathrm{~g}$ of poly(vinylpolypyrrolidone) and activated charcoal mixture $(1: 1, w / w)$ to eliminate pigments. Samples were homogenized in $300 \mu \mathrm{L}$ of cold extraction buffer [ $50 \mathrm{mM}$ sodium phosphate buffer ( $\mathrm{pH}$ 6.0) containing $1 \mathrm{mM}$ ethylenediamine tetraacetic acid, $1 \mathrm{mM}$ DL-dithiothreitol, $1 \mathrm{mM}$ phenylmethanesulfonyl fluoride]. The homogenate was centrifuged at $15000 \times g$ for $30 \mathrm{~min}$ at $4^{\circ} \mathrm{C}$. The GPOD activity was estimated by monitoring the formation of tetraguaiacol at $470 \mathrm{~nm}$ for $3 \mathrm{~min}$, as described previously by Stasolla and Yeung [35]. The reaction mixture consisted of $0.799 \mathrm{~mL}$ of $50 \mathrm{mM}$ sodium phosphate buffer ( $\mathrm{pH} 6.0$ ), $0.001 \mathrm{~mL}$ of $3 \mathrm{M}$ guaiacol, $0.1 \mathrm{~mL}$ of enzyme extract, and $0.1 \mathrm{~mL}$ of $0.3 \%(\mathrm{v} / \mathrm{v}) \mathrm{H}_{2} \mathrm{O}_{2}$. The enzyme activity was calculated using the molar extinction coefficient for tetraguaiacol $\left(26.6 \mathrm{mM}^{-1} \times \mathrm{cm}^{-1}\right)$.

\section{Foliar area and root length}

Young and old leaves were scanned in black/white $200 \mathrm{dpi}$ format using a HP F4280 scanner (Hewlett-Packard Company, Palo Alto, CA). The areas were calculated using Image J 1.43 software and the results were expressed in $\mathrm{cm}^{2}$. Lengths of the longest roots were measured using a ruler.

\section{Statistical analysis}

The results reported in tables and figures represent mean values $\pm S E$ of at least two independent experiments. For data related to copper content, leaf area, root length, chlorophyll content and betacyanin content in young leaves and roots, one-way analysis of variance (ANOVA) was performed and data transformation was used when was necessary $(\ln x)$. Pairwise comparisons were done using the Tukey test at $p<$ 0.05 . Kruskal-Wallis analysis followed by Dunn's test for comparisons of means was used only for analyses of betacyanin contents in old leaves. Student's t-test was used to evaluate the statistical significance of any differences in the GPOD activity data. All statistical analyses were done using the statistical software package SigmaStat ver. 3.5 (Systat Software Inc., San Jose, CA).

\section{Results}

\section{Copper content in roots and leaves}

At the beginning of treatment (day 0), young and old leaves of control plants $(0.3 \mu \mathrm{M})$ showed a copper content of 13.30 \pm 3.16 and $15.09 \pm 1.34 \mu \mathrm{g} \times \mathrm{g}^{-1} \mathrm{DW}$, respectively. The Tab. 1 shows that these copper contents in leaves of control plants did not change during the 6 days of incubation. After treatment of copper for 3 days, only $50 \mu \mathrm{M}$ of copper caused in young leaves an increase of $34 \%$ in the copper content. Whereas, the copper content in old leaves was not modified after treatment with copper for 3 and 6 days.

The copper content of old roots in control plants (day 0) was $71.30 \pm 15.67 \mu \mathrm{g} \times \mathrm{g}^{-1} \mathrm{DW}$. This copper content was ca. 4 times higher than those found in young and old leaves of control plants (day 0). Nonetheless, accumulation of the metal was evident in old roots from day 3 of treatment, and the extent of the accumulation was proportional to the increase of copper concentration in the nutrient solution. The maximum copper accumulation was found in old roots of plants treated with $250 \mu \mathrm{M}$ of copper for 6 days. This copper content is 208 -fold higher than that found in control roots (Tab. 1). In general, old roots had copper contents $1.8,85.6,221.5$, and 480.2-fold higher than those found in leaves of plants treated with $0.3 \mu \mathrm{M}$, $50 \mu \mathrm{M}, 100 \mu \mathrm{M}$, and $250 \mu \mathrm{M}$ of copper for 6 days, respectively. Due young roots were developed after 3 days of treatment, the copper content only was determined at day 6 and the highest copper content was found in plants treated with $250 \mu \mathrm{M}$ of copper (Tab. 1).

Tab. 1 Copper content in leaves and roots of Beta vulgaris L. plants treated with copper for 3 and 6 days.

\begin{tabular}{|c|c|c|c|c|}
\hline \multirow{3}{*}{$\begin{array}{c}\mathrm{CuSO}_{4} \\
(\mu \mathrm{M})\end{array}$} & \multicolumn{4}{|c|}{ Copper content $\left(\mu g \times g^{-1} D W\right)$} \\
\hline & \multicolumn{2}{|c|}{ Leaves } & \multicolumn{2}{|c|}{ Roots } \\
\hline & Old & Young & Old & Young \\
\hline \multicolumn{5}{|c|}{ Day 3} \\
\hline 0.3 & $17.05 \pm 3.26^{\mathrm{a}}$ & $14.09 \pm 0.20^{\mathrm{a}}$ & $35.12 \pm 3.88^{\mathrm{a}}$ & nd \\
\hline 50 & $18.40 \pm 2.32^{\mathrm{a}}$ & $18.84 \pm 0.92^{\mathrm{b}}$ & $730.12 \pm 251.75^{\mathrm{b}}$ & nd \\
\hline 100 & $23.19 \pm 2.67^{\mathrm{a}}$ & $16.39 \pm 1.51^{\mathrm{ab}}$ & $1860.47 \pm 22.23^{\mathrm{bc}}$ & nd \\
\hline 250 & $13.94 \pm 1.91^{\mathrm{a}}$ & $12.93 \pm 0.89^{\mathrm{a}}$ & $5333.69 \pm 1372.26^{c}$ & nd \\
\hline ANOVA: $\mathrm{F}$ & $2.30 \mathrm{~ns}$ & $9.29^{* * *}$ & $90.22^{* * \star}$ & \\
\hline \multicolumn{5}{|c|}{ Day 6} \\
\hline 0.3 & $15.19 \pm 3.15^{\mathrm{a}}$ & $14.72 \pm 2.59^{\mathrm{a}}$ & $42.11 \pm 15.21^{\mathrm{a}}$ & nd \\
\hline 50 & $19.41 \pm 3.07^{\mathrm{a}}$ & $18.41 \pm 2.68^{\mathrm{a}}$ & $1637.27 \pm 214.08^{b}$ & $922.80 \pm 127.67^{\mathrm{a}}$ \\
\hline 100 & $16.85 \pm 3.08^{\mathrm{a}}$ & $14.56 \pm 2.08^{\mathrm{a}}$ & $3495.67 \pm 980.79^{b c}$ & $1815.07 \pm 207.68^{\mathrm{a}}$ \\
\hline 250 & $20.22 \pm 2.59^{\mathrm{a}}$ & $16.42 \pm 2.81^{\mathrm{a}}$ & $8815.56 \pm 1456.79^{c}$ & $=1980.85 \pm 328.44^{\mathrm{a}}$ \\
\hline ANOVA: $\mathrm{F}$ & $0.56 \mathrm{~ns}$ & $0.50 \mathrm{~ns}$ & $76.88^{* * *}$ & $3.03 \mathrm{~ns}$ \\
\hline
\end{tabular}

Values are means $\pm S E$. Mean values in the same column followed by different letters are significantly different according to Tukey's test $(p<0.05)$. One-way ANOVA shows statistical significant difference at ${ }^{* * *} p<0.001$. nd - not determined; ns - statistically not different. 


\section{Effect of copper on chlorophyll content}

At the beginning of treatment (day 0 ) in control plants, the chlorophyll content in young leaves $\left(7.85 \mu \mathrm{g} \times \mathrm{disco}^{-1}\right)$ was $44 \%$ higher than that found in older ones $\left(5.45 \mu \mathrm{g} \times\right.$ disco $\left.^{-1}\right)$. These chlorophyll contents in young and old leaves of control plants were not modified after 6 days of incubation (Tab. 2).

After copper treatment, young leaves were characterized by a turgid appearance, whereas old leaves appeared chlorotic and dry (Fig. 1a,b). The chlorophyll content in young leaves did not change with exposure to increasing concentrations of copper and was always higher than that found in the old leaves. In old leaves treated with $50 \mu \mathrm{M}, 100 \mu \mathrm{M}$, and $250 \mu \mathrm{M}$ of copper, the respective chlorophyll contents were $32 \%, 39 \%$, and $57 \%$ lower of those in control plants (Tab. 2).

Tab. 2 Chlorophyll content in leaves and growth of leaves and roots in Beta vulgaris plants treated with copper for 6 days.

\begin{tabular}{|c|c|c|c|}
\hline $\mathrm{CuSO}_{4}(\mu \mathrm{M})$ & $\begin{array}{l}\text { Chlorophyll } \\
\left(\mu \mathrm{g} \times \operatorname{disc}^{-1}\right)\end{array}$ & Leaf area $\left(\mathrm{cm}^{2}\right)$ & Root length $(\mathrm{cm})$ \\
\hline \multicolumn{4}{|c|}{ Young } \\
\hline 0.3 & $8.75 \pm 0.30^{\mathrm{a}}$ & $41.30 \pm 1.92^{\mathrm{a}}$ & nd \\
\hline 50 & $9.59 \pm 0.55^{\mathrm{a}}$ & $36.26 \pm 1.48^{\mathrm{ab}}$ & nd \\
\hline 100 & $8.73 \pm 0.41^{\mathrm{a}}$ & $32.66 \pm 1.40^{\mathrm{bc}}$ & nd \\
\hline 250 & $9.26 \pm 0.36^{\mathrm{a}}$ & $29.28 \pm 0.94^{c}$ & nd \\
\hline ANOVA: F & $0.81 \mathrm{~ns}$ & $13.99^{\star \star \star}$ & \\
\hline \multicolumn{4}{|c|}{ Old } \\
\hline 0.3 & $5.00 \pm 0.36^{\mathrm{a}}$ & $5.10 \pm 0.14^{\mathrm{a}}$ & $21.85 \pm 0.61^{\mathrm{a}}$ \\
\hline 50 & $3.39 \pm 0.72^{\mathrm{b}}$ & $5.31 \pm 0.30^{\mathrm{a}}$ & $17.06 \pm 0.72^{\mathrm{b}}$ \\
\hline 100 & $3.04 \pm 0.26^{\mathrm{bc}}$ & $5.40 \pm 0.29^{\mathrm{a}}$ & $15.47 \pm 0.78^{\mathrm{b}}$ \\
\hline 250 & $2.14 \pm 0.26^{c}$ & $4.59 \pm 0.32^{\mathrm{a}}$ & $15.76 \pm 0.74^{\mathrm{b}}$ \\
\hline ANOVA: F & $16.72^{\star * *}$ & $1.63 \mathrm{~ns}$ & $16.77^{\star \star *}$ \\
\hline
\end{tabular}

Values are means $\pm S E$; chlorophyll content: $n=6-9$; leaf area: $n=$ 13-21; roots growth: $n=14-21$. Mean values in the same column followed by different superscript letters are significantly different according to Tukey's test $(p<0.05)$. One-way ANOVA shows statistical significant difference at ${ }^{* * *} p<0.001$. nd - not determined; ns - statistically not different.

\section{Differential effects of copper on leaf and root growth}

Leaf growth was differentially affected by copper, depending the age of the leaves. Young leaves of plants treated with 100 and $250 \mu \mathrm{M}$ of copper showed reductions in foliar surface areas of $21 \%$ and $29 \%$, respectively, in comparison to young leaves from control plants. In contrast, foliar surface areas of old leaves did not change in plants treated with copper (Tab. 2).

The root growth was reduced by $22 \%, 29 \%$, and $28 \%$ following exposure to $50 \mu \mathrm{M}, 100 \mu \mathrm{M}$, and $250 \mu \mathrm{M}$ of copper, respectively (Tab. 2). Another difference was the formation of young roots at the top of the principal roots of plants exposed to all concentrations of copper tested.

\section{Effect of copper on lipid peroxidation}

In control plants incubated for 3 and 6 days, the level of lipid peroxidation was 1.4-fold higher in old leaves than in young leaves (Fig. 2a,b). The lipid peroxidation in young leaves was increased 3.9, 3.4 and 5.8 times with exposure to $50 \mu \mathrm{M}, 100$ $\mu \mathrm{M}$, and $250 \mu \mathrm{M}$ of copper for 3 days. Even though the average value of lipid peroxidation in young leaves treated for 3 days with $250 \mu \mathrm{M}$ of copper is higher than that found with $100 \mu \mathrm{M}$ of copper, data of treatment with $250 \mu \mathrm{M}$ have high dispersion and did not show statistically significant difference.

The lipid peroxidation in young leaves of plants treated with 50 and $100 \mu \mathrm{M}$ of copper for 3 days remained at the same level until day 6 (Fig. 2a). However, the level lipid peroxidation was reduced in young leaves of plants exposed to $250 \mu \mathrm{M}$ of copper for 6 days. Unlike young leaves, old leaves did not show any change in the lipid peroxidation with copper treatment (Fig. 2b).

\section{Differential accumulation of betacyanin}

Young and old leaves of control plants $(0.3 \mu \mathrm{M})$ showed a low level of betacyanin after 3 and 6 days of incubation (Fig. 3). Copper treatment induced in young leaves the development of red pigmentation associated with the betacyanin content (Fig. 1a). Young leaves accumulated betacyanin after 3 days of copper treatment. Maximum accumulation was observed after 6 days of copper treatment, with betacyanin contents 5.2-, 5.7-, and 6.4-fold higher than that found in the control (Fig. 3a). In contrast, the level of betacyanin in old leaves increased until day 6. Betacyanin contents were 3.6, 4.8, and 3 times lower than those found in young leaves at the same copper concentrations (Fig. 3b).

At the beginning of treatment in control plants, old roots showed a yellow-red pigmentation and betacyanin contents did not change during the incubation period. After copper treatment, old roots developed a dark-brown pigmentation and this change in pigmentation correlated with a decrease in betacyanin content (Fig. 4). In contrast, young roots developed in plants treated with copper for 6 days showed a red-violet pigmentation and accumulated betacyanin at levels close to 30 $\mathrm{mg} \times \mathrm{g}^{-1} F W$ with all copper concentrations (Fig. 1d, Fig. 4). This mean betacyanin content was 2.6- and 5.9-fold higher than the highest betacyanin contents found in leaves and old roots, respectively (Fig. 3, Fig. 4).

\section{Activity of GPOD}

At the beginning of treatment (day 0), young and old leaves of the control plants showed GPOD activities of 0.15 and 0.07 $\mu$ moles $\times \min ^{-1} \times \mathrm{g}^{-1} \mathrm{FW}$, respectively. This GPOD activity in old leaves increased 2.8-fold after 6 days of incubation, whereas in young leaves did not change (Fig. 5).

The treatment with $50 \mu \mathrm{M}$ of copper causes a negative effect on root growth, chlorophyll content and lipid peroxidation. Likewise, this copper concentration induced betacyanin accumulation. Thus, we decided that this concentration is adequate to evaluate defense responses to copper stress, such as GPOD activity. GPOD activity in young leaves increased 3.3-fold with the copper exposure for 3 days, and was sustained until day 6 (Fig. 5a). GPOD activity was also enhanced 1.4-fold after 3 days of copper treatment and did not change at day 6 (Fig. 5b).

\section{Discussion}

Plants have developed mechanisms to maintain the appropriate concentrations of metals ions in different plant organs and cellular compartments. The exposure to high levels 


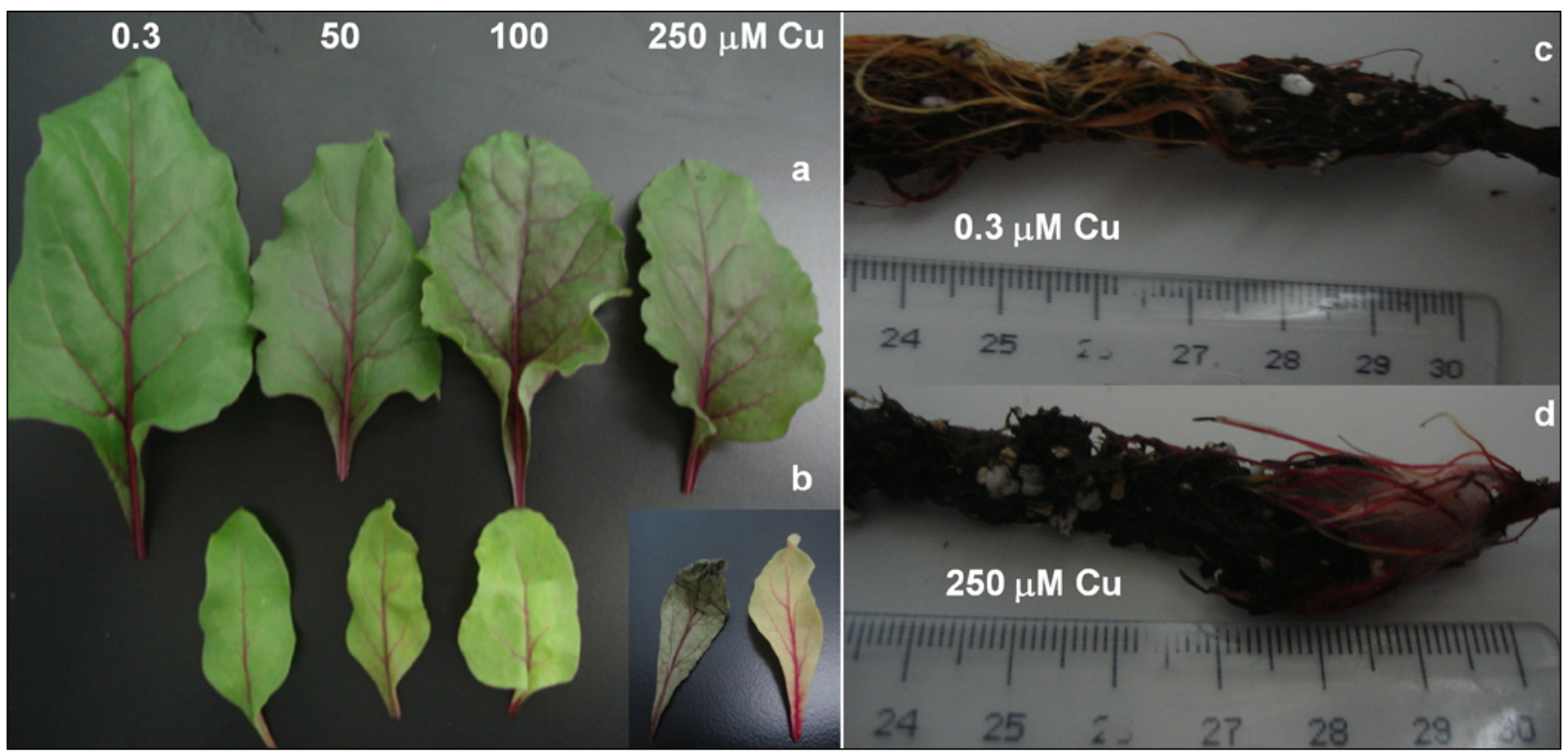

Fig. 1 Chlorosis, red pigmentation and growth of plants treated with copper $(\mathrm{Cu})$ for 6 days. a Young leaves. b Old leaves. c Control roots. d Roots treated with copper.

essential metals ions, such as copper activates in plants the homeostatic mechanism to minimize the toxic effects of metal. The retention of metals in roots to prevent their translocation to shoots is a strategy used by many plants to tolerate heavy metal stress [36]. The accumulation of copper was evident in B. vulgaris roots with exposure to copper for 6 days, but the metal was not translocated to leaves (Tab. 1). Similar results have been reported for Brassica napus, where copper content increased in the roots, but not in the leaves throughout the course of exposure to elevated levels of copper [37]. Lequeux et al. [6] suggested that the lignin accumulation in cell walls of endodermis or xylem limits copper efflux from the vascular cylinder to the shoot. Accordingly, exposure of M. chamomilla plants to copper was associated with increased lignin deposition in the roots [23]. Forty percent of the copper retained in the roots of rice plants results from immobilization of the metal in the cell wall [38]. Cysteine-rich proteins that bind copper to form stable complexes have been detected in the cell walls, vesicles, and cytoplasm of meristematic cells in the root of Allium sativum after copper treatment [5].

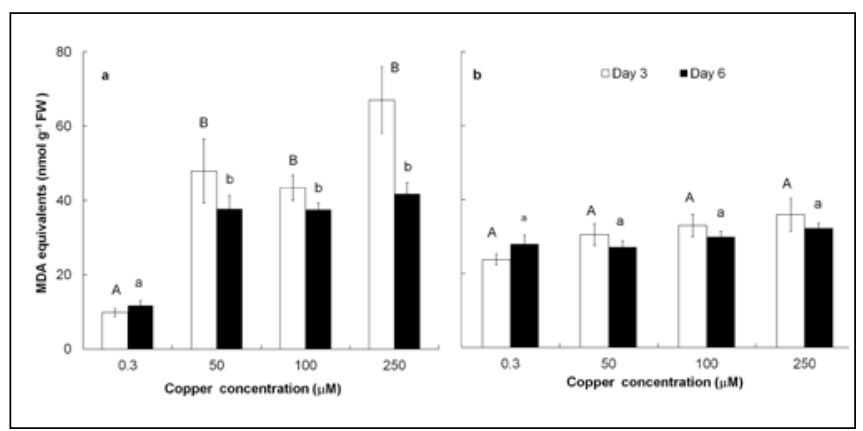

Fig. 2 a Lipid peroxidation in young leaves of Beta vulgaris L. plants treated with copper for 3 days (white bars) and 6 days (black bars); $\mathbf{b}$ in old leaves. Values are means $\pm S E$; young leaves: $n=5-11$, old leaves: $n=6-12$. Different letters above the bars indicate statistical significant differences between treatments $(p<0.05)$ according to Tukey's test.
Old leaves of control plants had consistently less chlorophyll than young leaves. The observation that the level of lipid peroxidation in old leaves was higher than that found in young leaves at either day 3 or day 6 (Tab. 2, Fig. 2) further suggests that the old leaves used in this study may already have been in the early stages of senescence when treatment began. Given that senescence is a catabolic process that leads to nutrient recycling, chloroplast degeneration is one of the earliest events in the process. It is accompanied by a decrease in photosynthetic activity, chlorophyll degradation, and protein loss [39].

Chlorophyll content in old leaves of $B$. vulgaris plants decreased progressively with the increase of copper concentration, with the leaves turning completely yellow and sometimes dying at the highest copper concentration tested. In young leaves treated with copper, chlorophyll content did not change and the leaves remained turgid (Fig. 1, Tab. 2). Therefore, consistent with previous studies that demonstrated a connection between copper-induced senescence and the developmental stage of the leaves $[9,22]$; we observed that copper accelerated the senescence of old leaves, but not had effect on young leaves.

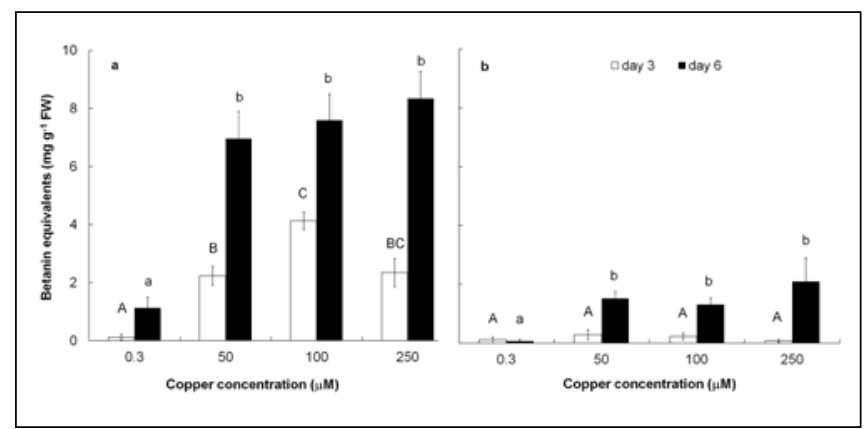

Fig. 3 a Betacyanin content in young leaves of Beta vulgaris L. plants treated with copper for 3 days (white bars) and 6 days (black bars); b in old leaves. Values are means $\pm S E(n=4-10)$. Different letters above bars indicate statistical significant differences between treatments $(p$ $<0.05)$ according to Tukey's test. 


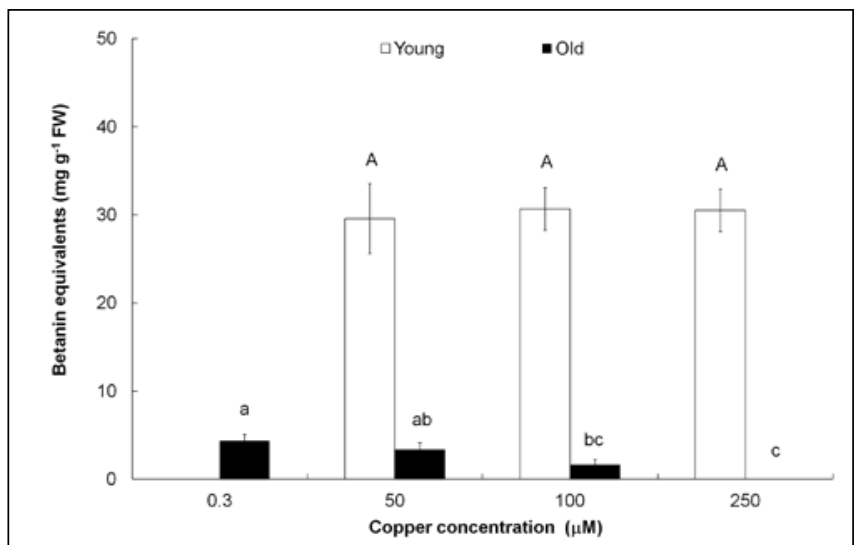

Fig. 4 Betacyanin content in young (white bars) and old (black bars) roots of Beta vulgaris L. plants treated with copper for 6 days. Values are mean $\pm S E(n=5-9)$. Different letters above bars indicate statistical significant differences between treatments $(p<0.05)$ according to Tukey's test.

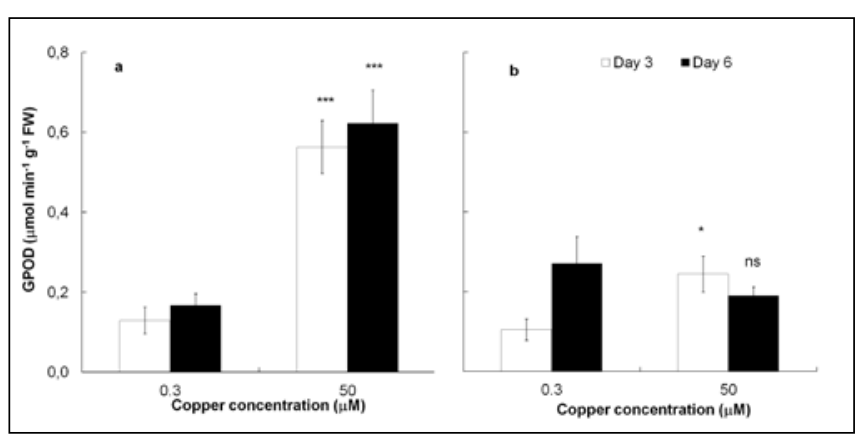

Fig. 5 a GPOD activity in young leaves of Beta vulgaris L. plants treated with copper for 3 days (white bars) and 6 days (black bars); b in old leaves. Values are mean $\pm S E$; young leaves: $n=6$; old leaves: $n=3-7 .^{*}$ and ${ }^{* * *}$ - statistically different from the control at $p<0.05$ and $p<0.001$; ns - statistically not different, according to Student's t-test $(p<0.05)$.

Although copper was not translocated to leaves, the differential betacyanin accumulation was evident in young and old leaves from plants treated with copper, whereas betacyanin levels remained unchanged in young and old leaves of control plants (Tab. 1, Fig. 3). The accumulation of betacyanin in young leaves, which was evident at day 3 and day 6 after the beginning of treatment, was accompanied by increases in lipid peroxidation (Fig. 2a, Fig. 3a). In old leaves, betacyanins accumulated until day 6 , although their levels were lower than those found in young leaves from plants exposed to the same copper concentrations. Moreover, copper had no effect on rates of lipid peroxidation in old leaves (Fig. 2b, Fig. 3b). These results suggest that betacyanin accumulation in young leaves of $B$. vulgaris may be a defense response to copper-induced oxidative stress, and that a signal molecule may be transferred from roots to leaves. Accordingly, Russo et al. [37] reported an increase in the level of reduced glutathione and the induction of glutathione reductase activity in Brassica napus leaves, where no translocation of copper occurred. In Phaseolus vulgaris leaves, increases in the amount of reduced ascorbate and the activities of the enzymes monodehydroascorbate reductase and dehydroascorbate reductase were observed before the accumulation of copper in leaves [40]. Studies involving $A$. thaliana plants exposed to copper suggest that oxylipins or jasmonates could be involved in this interorgan signaling through the lipoxygenase genes expression $[41,42]$.

Results of this study shown that organ age also affected the accumulation of betacyanin in B. vulgaris roots exposed to copper. Betacyanin content decreased in old roots with the increase in the copper content. However, new roots that were formed as result of copper treatment showed the highest betacyanin content of any of the plant organs we tested (Fig. 4). Similar to the copper effect observed in leaves, results in roots suggest that betacyanin are accumulated in actively growing organs. Accordingly, Skórzyńska-Polit et al. [24] found that copper induced higher rates of flavonol accumulation in young leaves than in old leaves of $P$. coccineus plants.

Age-dependent differences in the effects of copper stress on leaves have been reported for other factors capable of causing oxidative stress. In Pisum sativum plants exposed to the herbicide paraquat, the youngest and more photosynthetically active leaves were less susceptible to injury than older leaves, possibly as a result of higher basal levels of transcripts and activities of the antioxidant enzymes superoxide dismutase and glutathione reductase [43]. Relative to younger leaves, old tobacco leaves showed constitutively lower levels of antioxidant compounds and higher levels of $\mathrm{H}_{2} \mathrm{O}_{2}$ that resulted in photooxidative stress following exposure to paraquat [44]. Non-enzymatic antioxidants were also activated differentially in young and mature leaves of $A$. thaliana subjected to drought stress. Young leaves showed an increase in anthocyanin content and less photooxidative stress [45]. All of these studies showed that young leaves have an active defense system that ensures plant survival under stressful conditions.

The results obtained in this work show for first time that betacyanin accumulation is induced by copper stress in planta. Secondary metabolites may contribute to antioxidant defense responses to copper stress in plants. Copper-induced accumulation of chlorogenic acid in M. chamomilla leaves could prevent lipid peroxidation [12]. Pre-treatment of leaf segments with the polyamine spermine prevented the loss of glutathione reductase enzyme activity and reduced increases in levels of lipid peroxidation and $\mathrm{H}_{2} \mathrm{O}_{2}$ content induced by copper [13].

It has been suggested that betacyanin accumulation in $B$. vulgaris plants may contribute to counteracting the oxidative stress caused by wounding and bacterial infiltration [29]. Similarly, watering the roots of Suaeda salsa with $\mathrm{H}_{2} \mathrm{O}_{2}$ induces betacyanin synthesis in leaves [31]. However, other components of the antioxidant system of $B$. vulgaris L. plants may also be involved in the higher tolerance to copper stress of young organs compared with older ones. Our results show that induction of GPOD activity and lipid peroxidation in copper-treated plants was higher in young leaves than in old leaves (Fig. 2a, Fig. 5a). Consistent with these findings, Mediouni et al. [10] reported an increase in both levels of MDA and GPOD activity in leaves of Solanum lycopersicon plants exposed to elevated levels of copper. Some authors suggested a role for GPOD enzymes in scavenging ROS or mediating the lignification of cell walls in copper exposed plants $[11,17,18]$. Sgherri et al. [14] have proposed a hypothetical $\mathrm{H}_{2} \mathrm{O}_{2}$ scavenging system that comprises phenolics and peroxidase enzymes. The antioxidant activity of betacyanin has been demonstrated in vitro, and betacyanin oxidation by peroxidases of $B$. vulgaris roots has been described $[26,27,46]$. The betacyanin-peroxidase system may thus be part of an antioxidant response in $B$. vulgaris 
plants to copper stress. However, studies about the activation of enzymes involved on betacyanin synthesis and the levels of ROS are needed to analyze the role of these metabolites in tolerance of young leaves to metal stress.

The inhibition of leaf growth of $B$. vulgaris plants also varied with age. Whereas copper inhibited the growth of young leaves, the sizes of old leaves did not change upon exposure to copper (Tab. 2). These results indicated a differential effect with the leaf age. The most likely explanation for this observation is that whereas old leaves were totally expanded when the copper treatment was applied, young leaves were in the process of expanding. Pasternak et al. [3] attributed the decrease in growth of $A$. thaliana leaves to the effect of copper on cell expansion. Accordingly, leaves of Phaseolus coccineus in a stage of intensive growth showed reduced foliar surface areas and fresh weights after copper treatment. The metal caused chlorosis in older leaves but the foliar surface areas were unaffected [19]. The results in B. vulgaris leaves suggest the participation of a signal molecule, which is transported from roots to leaves and triggers a series of events leading to inhibition of leaf expansion in young leaves and accelerated senescence in old leaves.

Inhibition of root growth in B. vulgaris L. correlated with the increasing copper accumulation in this organ (Tab. 1, Tab. 2). Previous studies showed that copper accumulation in Zea mays roots led to the inhibition of cell division and root growth [4]. Moreover, growth inhibition of primary and lateral roots in copper-exposed A. thaliana plants was related to a decrease in viability of the apex cells [6]. Copper exposure also inhibited cell elongation, thereby reducing root diameter in Sorghum bicolor [47]. A decrease in the mitotic indices of meristematic cells of $A$. sativum roots was accompanied by degenerative changes that finally led to disruption of nuclear membranes, disintegration of organelles and cell death [5].

Elevated levels of copper in B. vulgaris L. induced the emergence of new short roots with red pigmentation (Fig. 1d). In addition to phytotoxic effects on roots, copper excess triggers reorganization of the radical system. According to Lequeux et al. [6], changes in the distributions of auxin and cytokinin are involved in remodeling of the A. thaliana root system. Furthermore, treatment with tert-butyl hydroperoxide, an analogue of $\mathrm{H}_{2} \mathrm{O}_{2}$, resulted in similar root architecture to that obtained in A. thaliana plants treated with copper, suggesting the participation of ROS in the control of these morphological changes induced by stress [3].

We conclude that the copper accumulated in B. vulgaris $\mathrm{L}$. roots may activate a signaling process to the leaf and triggers a series of events that promote oxidative damage in young leaves and accelerate the senescence of older leaves. The betacyanin accumulation and GPOD activity in actively growing organs are induced as a defense response to oxidative damage caused by copper.

\section{Acknowledgements}

This research project was financially supported by SIP (Grant 20111038) and CONACYT (Grant 49950-Z). We thank Dr. A. René Arzuffi Barrera for assisting in statistical analyses and Dr. Kalina Bermúdez Torres for helpful discussions. Janet M. León Morales thanks CONACYT (171078) and PIFIIPN for fellowships awarded. G. Sepúlveda-Jiménez and M. Rodríguez-Monroy thank EDI and SIBE-IPN.

\section{References}

1. Nagajyoti PC, Lee KD, Sreekanth TVM. Heavy metals, occurrence and toxicity for plants: a review. Environ Chem Lett. 2010;8(3):199-216. http://dx.doi.org/10.1007/ s10311-010-0297-8

2. Salisbury FB, Ross CW. Plant physiology. Belmont CA: Wadsworth Pub. Co.; 1992. (vol 1).

3. Pasternak T, Rudas V, Potters G, Jansen M. Morphogenic effects of abiotic stress: reorientation of growth in seedlings. Environ Exp Bot. 2005;53(3):299-314. http://dx.doi. org/10.1016/j.envexpbot.2004.04.009

4. Jiang W, Liu D, Liu X. Effects of copper on root growth, cell division, and nucleolus of Zea mays. Biol Plant. 2001;44(1):105109. http://dx.doi.org/10.1023/A:1017982607493

5. Liu D, Jiang W, Meng Q, Zou J, Gu J, Zeng M. Cytogenetical and ultrastructural effects of copper on root meristem cells of Allium sativum L. Biocell. 2009;33:25-32.

6. Lequeux H, Hermans C, Lutts S, Verbruggen N. Response to copper excess in Arabidopsis thaliana: impact on the root system architecture, hormone distribution, lignin accumulation and mineral profile. Plant Physiol Biochem. 2010;48(8):673-682. http://dx.doi.org/10.1016/j. plaphy.2010.05.005

7. Zhang H, Xia Y, Wang G, Shen Z. Excess copper induces accumulation of hydrogen peroxide and increases lipid peroxidation and total activity of copper-zinc superoxide dismutase in roots of Elsholtzia haichowensis. Planta. 2007;227(2):465-475. http://dx.doi.org/10.1007/ s00425-007-0632-x

8. Maksymiec W. Signaling responses in plants to heavy metal stress. Acta Physiol Plant. 2007;29(3):177-187. http:// dx.doi.org/10.1007/s11738-007-0036-3

9. Drażkiewicz M, Skórzyńska-Polit E, Krupa Z. Copperinduced oxidative stress and antioxidant defence in Arabidopsis thaliana. BioMetals. 2004;17(4):379-387. http:// dx.doi.org/10.1023/B:BIOM.0000029417.18154.22

10. Mediouni C, Ammar WB, Houlné G, Chabouté ME, Jemal F. Cadmium and copper induction of oxidative stress and antioxidative response in tomato (Solanum lycopersicon) leaves. Plant Growth Regul. 2008;57(1):89-99. http:// dx.doi.org/10.1007/s10725-008-9324-1

11. Khatun S, Ali MB, Hahn EJ, Paek KY. Copper toxicity in Withania somnifera: Growth and antioxidant enzymes responses of in vitro grown plants. Environ Exp Bot. 2008;64(3):279-285. http://dx.doi.org/10.1016/j. envexpbot.2008.02.004

12. Kováčik J, Grúz J, Bačkor M, Tomko J, Strnad M, Repčák M. Phenolic compounds composition and physiological attributes of Matricaria chamomilla grown in copper excess. Environ Exp Bot. 2008;62(2):145-152. http://dx.doi. org/10.1016/j.envexpbot.2007.07.012

13. Groppa MD, Tomaro ML, Benavides MP. Polyamines and heavy metal stress: the antioxidant behavior of spermine in cadmium- and copper-treated wheat leaves. BioMetals. 2006;20(2):185-195. http://dx.doi.org/10.1007/ s10534-006-9026-y

14. Sgherri C, Cosi E, Navari-Izzo F. Phenols and antioxidative status of Raphanus sativus grown in copper excess. Physiol Plant. 2003;118(1):21-28. http://dx.doi. org/10.1034/j.1399-3054.2003.00068.x

15. Jouili H, Bouazizi H, El Ferjani E. Plant peroxidases: biomarkers of metallic stress. Acta Physiol Plant. 
2011;33(6):2075-2082. http://dx.doi.org/10.1007/ s11738-011-0780-2

16. Chaoui A, Jarrar B, EL Ferjani E. Effects of cadmium and copper on peroxidase, NADH oxidase and IAA oxidase activities in cell wall, soluble and microsomal membrane fractions of pea roots. J Plant Physiol. 2004;161(11):1225-1234. http://dx.doi.org/10.1016/j.jplph.2004.02.002

17. Zhang H, Zhang F, Xia Y, Wang G, Shen Z. Excess copper induces production of hydrogen peroxide in the leaf of Elsholtzia haichowensis through apoplastic and symplastic CuZn-superoxide dismutase. J Hazard Mater. 2010;178(1-3):834-843. http://dx.doi.org/10.1016/j. jhazmat.2010.02.014

18. Lin CC, Chen LM, Liu ZH. Rapid effect of copper on lignin biosynthesis in soybean roots. Plant Sci. 2005;168(3):855861. http://dx.doi.org/10.1016/j.plantsci.2004.10.023

19. Maksymiec W, Russa R, Urbanik-Sypniewska T, Baszynski T. Effect of excess $\mathrm{Cu}$ on the photosynthetic apparatus of runner bean leaves treated at two different growth stages. Physiol Plant. 1994;91(4):715-721. http://dx.doi. org/10.1111/j.1399-3054.1994.tb03010.x

20. Vinit-Dunand F, Epron D, Alaoui-Sossé B, Badot PM. Effects of copper on growth and on photosynthesis of mature and expanding leaves in cucumber plants. Plant Sci. 2002;163(1):53-58. http://dx.doi.org/10.1016/ S0168-9452(02)00060-2

21. Luna CM, González CA. Oxidative damage caused by an excess of copper in oat leaves. Plant Cell Physiol. 1993;35:11-15.

22. Tewari RK, Kumar P, Sharma PN. Antioxidant responses to enhanced generation of superoxide anion radical and hydrogen peroxide in the copper-stressed mulberry plants. Planta. 2005;223(6):1145-1153. http://dx.doi.org/10.1007/ s00425-005-0160-5

23. Kováčik J, Bačkor M, Kaduková J. Physiological responses of Matricaria chamomilla to cadmium and copper excess. Environ Toxicol. 2008;23(1):123-130. http://dx.doi. org/10.1002/tox.20315

24. Skórzyńska-Polit E, Drażkiewicz M, Wianowska D, Maksymiec W, Dawidowicz AL, Tukiendorf A. The influence of heavy metal stress on the level of some flavonols in the primary leaves of Phaseolus coccineus. Acta Physiol Plant. 2004;26(3):247-254. http://dx.doi.org/10.1007/ s11738-004-0014-y

25. Strack D, Steglich W, Wray V. Betalains. In: Waterman PG, editor. Methods in plant biochemistry. New York: Academic Press; 1993. p. 421-450. (vol 8).

26. Escribano J, Pedreño MA, García-Carmona F, Muñoz R. Characterization of the antiradical activity of betalains from Beta vulgaris L. roots. Phytochem Anal. 1998;9(3):124-127. http://dx.doi.org/10.1002/(SICI)10991565(199805/06)9:3<124::AID-PCA401>3.0.CO;2-0

27. Kanner J, Harel S, Granit R. Betalains: a new class of dietary cationized antioxidants. J Agric Food Chem. 2001;49(11):5178-5185. http://dx.doi.org/10.1021/ jf010456f

28. Ibdah M, Krins A, Seidlitz HK, Heller W, Strack D, Vogt T. Spectral dependence of flavonol and betacyanin accumulation in Mesembryanthemum crystallinum under enhanced ultraviolet radiation. Plant Cell Environ. 2002;25(9):11451154. http://dx.doi.org/10.1046/j.1365-3040.2002.00895.x

29. Sepúlveda-Jiménez G, Rueda-Benítez P, Porta H, RochaSosa M. Betacyanin synthesis in red beet (Beta vulgaris) leaves induced by wounding and bacterial infiltration is preceded by an oxidative burst. Physiol Mol Plant Pathol. 2004;64(3):125-133. http://dx.doi.org/10.1016/j. pmpp.2004.08.003

30. Wang CQ, Zhao JQ, Chen M, Wang BS. Identification of betacyanin and effects of environmental factors on its accumulation in halophyte Suaeda salsa. J Plant Physiol Mol Biol. 2006;32:195-201.

31. Wang CQ, Chen M, Wang BS. Betacyanin accumulation in the leaves of C3 halophyte Suaeda salsa L. is induced by watering roots with $\mathrm{H}_{2} \mathrm{O}_{2}$. Plant Sci. 2007;172(1):1-7. http://dx.doi.org/10.1016/j.plantsci.2006.06.015

32. Lichtenthaler HK. Chlorophylls and carotenoids: pigments of photosynthetic biomembranes. Method Enzymol. 1987;148:350-382. http://dx.doi. org/10.1016/0076-6879(87)48036-1

33. Alia, Prasad KVSK, Pardha Saradhi P. Effect of zinc on free radicals and proline in Brassica and Cajanus. Phytochemistry. 1995;39(1):45-47. http://dx.doi. org/10.1016/0031-9422(94)00919-K

34. Schwartz SJ, Von Elbe JH. Quantitative determination of individual betacyanin pigments by high-performance liquid chromatography. J Agric Food Chem. 1980;28(3):540-543. http://dx.doi.org/10.1021/jf60229a032

35. Stasolla C, Yeung EC. Cellular ascorbic acid regulates the activity of major peroxidases in the apical poles of germinating white spruce (Picea glauca) somatic embryos. Plant Physiol Biochem. 2007;45(3-4):188-198. http://dx.doi. org/10.1016/j.plaphy.2007.02.007

36. Fernandes JC, Henriques FS. Biochemical, physiological, and structural effects of excess copper in plants. Bot Rev. 1991;57(3):246-273. http://dx.doi.org/10.1007/BF02858564

37. Russo M, Sgherri C, Izzo R, Navari-Izzo F. Brassica napus subjected to copper excess: phospholipases $\mathrm{C}$ and $\mathrm{D}$ and glutathione system in signalling. Environ Exp Bot. 2008;62(3):238-246. http://dx.doi.org/10.1016/j. envexpbot.2007.09.003

38. Chen CT, Chen TH, Lo KF, Chiu CY. Effects of proline on copper transport in rice seedlings under excess copper stress. Plant Sci. 2004;166(1):103-111. http://dx.doi. org/10.1016/j.plantsci.2003.08.015

39. Lim PO, Nam HG. Aging and senescence of the leaf organ. J Plant Biol. 2007;50(3):291-300. http://dx.doi.org/10.1007/ BF03030657

40. Cuypers A, Vangronsveld J, Clijsters H. Biphasic effect of copper on the ascorbate-glutathione pathway in primary leaves of Phaseolus vulgaris seedlings during the early stages of metal assimilation. Physiol Plant. 2000;110(4):512-517. http://dx.doi.org/10.1111/j.1399-3054.2000.1100413.x

41. Remans T, Opdenakker K, Smeets K, Mathijsen D, Vangronsveld J, Cuypers A. Metal-specific and NADPH oxidase dependent changes in lipoxygenase and NADPH oxidase gene expression in Arabidopsis thaliana exposed to cadmium or excess copper. Funct Plant Biol. 2010;37(6):532. http://dx.doi.org/10.1071/FP09194

42. Cuypers A, Smeets K, Ruytinx J, Opdenakker K, Keunen E, Remans T, et al. The cellular redox state as a modulator in cadmium and copper responses in Arabidopsis thaliana seedlings. J Plant Physiol. 2011;168(4):309-316. http:// dx.doi.org/10.1016/j.jplph.2010.07.010

43. Donahue JL, Okpodu CM, Cramer CL, Grabau EA, Alscher RG. Responses of antioxidants to paraquat in pea leaves (relationships to resistance). Plant Physiol. 
1997;113(1):249-257. http://dx.doi.org/10.1104/ pp.113.1.249

44. Ohe M, Rapolu M, Mieda T, Miyagawa Y, Yabuta Y, Yoshimura $\mathrm{K}$, et al. Decline in leaf photooxidative-stress tolerance with age in tobacco. Plant Sci. 2005;168(6):1487-1493. http://dx.doi.org/10.1016/j.plantsci.2005.01.020

45. Jung S. Variation in antioxidant metabolism of young and mature leaves of Arabidopsis thaliana subjected to drought. Plant Sci. 2004;166(2):459-466. http://dx.doi.org/10.1016/j. plantsci.2003.10.012

46. Martínez-Parra J, Muñoz R. Characterization of betacyanin oxidation catalyzed by a peroxidase from Beta vulgaris L. roots. J Agric Food Chem. 2001;49(8):4064-4068. http:// dx.doi.org/10.1021/jf0013555

47. Kasim WA. Changes induced by copper and cadmium stress in the anatomy and grain yield of Sorghum bicolor (L.) Moench. Int J Agri Biol. 2006;8:123-128. 